\title{
Medical Induction for Mid trimester Abortion: A Hospital-Based Descriptive Cross-sectional Study
}

\author{
Jyotshna Sharma, ${ }^{1}$ Sanjeeb Tiwari, ${ }^{2}$ Manoj Pokhrel, ${ }^{1}$ Lhakpa Lama' \\ 'Department of Obstetrics and Gyanecology, Kathmandu Medical College-Teaching Hospital, Kathmandu, Nepal, \\ ${ }^{2}$ Department of General Practice and Emergency Medicine, Maharajgunj Medical Campus, Institute of Medicine, \\ T.U., Maharajguni, Kathmandu, Nepal.
}

\section{ABSTRACT}

Introduction: Second trimester abortion is known as termination of pregnancy from 13- 28 weeks of gestation which can be further divided into early second trimester as 13-22 weeks and late as 23-28 weeks. In our study we have limited up to early second trimester. We intend to see the success rate of combination of mifepristone and misoprostol for medical induction, median time required for expulsion, complication and need of dilation and evacuation in some cases. This study also aims to give a review of current literature in mid trimester abortion with respect to efficacy, complication and also to provide evidencebase recommendation for safe regimens for mid trimester pregnancy termination.

Methods: This was hospital-based descriptive cross-sectional study conducted among 40 pregnant women at second trimester admitted for termination of pregnancy in Kathmandu medical collage teaching hospital for the period of six month. Ethical approval was taken from the Institutional Review Committee of Kathmandu Medical College (Ref: 2207202002). Convenient sampling was done. All the pregnant women who need to terminate their pregnancy at second trimester (13-22weeks) were admitted at Kathmandu Medical College Teaching hospital for termination of pregnancy were included in the study.

Results: Among the 40 women, who had termination of pregnancy at second trimester 37(92.5\%) had successful medical termination whereas $3(7.5 \%)$ needed dilatation and evacuation.

Conclusions: The combination of Mifepristone and Misoprostol have excellent result for termination of pregnancy if appropriately used after evaluating the patient with minimal complications.

\section{Keywords: abortion; dilation and evacuation; medical induction.}

\section{INTRODUCTION}

More than one third of pregnancies occurring worldwide are unwanted in which $20 \%$ ends up in termination of pregnancy. ${ }^{1,2}$ About $10-15 \%$ of abortion happen in second trimester and this accounts for more than twothird of major complication. ${ }^{3,4,5}$ In order to reduce the complications by surgery, the use of mifepristone and misoprostol (MI) has been considered to be successful and effective method for termination of second trimester abortion. ${ }^{6,7,8}$ With the combined regimen, the median time for expulsion is between six and nine hours. ${ }^{9,10}$
Second trimester abortion has been offered in high level facilities by specialists. These factors have resulted in limiting the availability and reach of medical abortion beyond 12 week despite of growing evidence demonstrating to be safe and effective. MI has been considered as effective method for termination of

Correspondence: Dr. Jyotshna Sharma, Department of Obstetrics and Gynaecology, Kathmandu Medical College Teaching Hospital, Sinamangal, Kathmandu, Nepal. Email: jyotszee@gmail. com, Phone: +977-9851137722. 
pregnancy which can really help the doctors practicing in remote part of Nepal with minimal resources.

The aim of the study is to study the success rate of combination of mifepristone and misoprostol for medical induction, mediantimerequired for expulsion, complication and need of dilation and evacuation in some cases.

\section{METHODS}

This was a hospital-based descriptive cross-sectional study conducted from 1 st of October 2019 to 30th of March 2020 for six months period at Kathmandu Medical College Teaching Hospital. Ethical approval was obtained from the Institutional Review Committee of Kathmandu Medical College (Ref: 2207202002). All the pregnant women who need to terminate their pregnancy at second trimester (13-22weeks) were admitted at Kathmandu Medical College Teaching Hospital for termination of pregnancy were included in the study. The convenient sampling method was used. The sample size was calculated by using formula,

$\mathrm{n}=\mathrm{Z2} \times \mathrm{p} \times \mathrm{q} / \mathrm{e} 2$

Where,

$\mathrm{n}=$ Sample size,

$Z=1.96$ at $95 \%$ Confidence Interval,

$p=0.05$

$q=1-p=0.85$

$\mathrm{e}=$ Margin of error, $7 \%$

$\mathrm{n}=(1.96) 2 \times 0.05 \times(1-0.05) /(0.07) 2$

$=.182476 / .0049=37.24$

Although sample size calculated was 38, total participants included were 40 . Women who came to $\mathrm{KMCTH}$ for termination of intrauterine pregnancy of 13-
22 weeks by last menstrual period and confirmed by ultrasound were included in the study. Those women with allergies or have contraindication to mifepristone and misoprostol were excluded from the study. Once the women were counselled and consented for termination of pregnancy, informed written consent was taken from the participants. Detailed clinical history was taken and participants were given the one tablet of mifepristone $200 \mathrm{mg}$ to be taken with water and participants were given two tablets of misoprostol $400 \mathrm{mg}$ to be taken after one day sublingually at early morning and asked to come to hospital within 1 hour of taking misoprostol. Once participants arrived at hospital repeat doses of misoprostol was given in three hourly duration from the initial dose of misoprostol till expulsion of fetus and placenta. All women were given medication for pain.

Timing of misoprostol, number of doses of misoprostol required, pain medication, induction to expulsion time and bleeding were noted and filled in the Performa. All data were entered and analyzed using SPSS 17 . The descriptive statistical analysis was done; frequency and percentages were calculated for binary variable whereas mean, median and standard deviation were calculated for continuous variable.

\section{RESULTS}

In our study the total of forty women underwent second trimester abortion. The range of age was from 18 to 38 years, mean age being 27.45 years (SD- 4.93 ) (Table 1). The participants were from gravida 1 to 4 and mean being 2.38 (SD-0.868) mode being 2. Ninety five percent $(n=38)$ of women are multipara. Among 40 women $4(10 \%)$ had previous experience of abortion, $6(15 \%)$ had previous one cesarean section for prior delivery. The gestational age of the participants was from 13-20 weeks and mean being 15.435 (SD-1.889). Minimal dose of Misoprostol was 1 and 5 being the maximal dose, mean being 2.48 (SD-0.751). After 2

Table 1. Descriptive Statistics on abortion, gestational age and misoprostol dose.

\begin{tabular}{|l|l|l|l|l|l|l|l|l|}
\hline S.N & & Age & Gravida & Parity & Abortion & $\begin{array}{l}\text { Gestational } \\
\text { Age }\end{array}$ & $\begin{array}{l}\text { Misoprostol } \\
\text { Dose }\end{array}$ & $\begin{array}{l}\text { Time } \\
\text { Duration }\end{array}$ \\
\hline 1. & $\mathrm{~N} \mathrm{Valid}$ & 40 & 40 & 40 & 40 & 40 & 40 & 37 \\
\hline 2. & Missing & 0 & 0 & 0 & 0 & 0 & 0 & 3 \\
\hline 3. & Mean & 27.45 & 2.38 & .10 & 1.80 & 15.453 & 2.48 & 7.215 \\
\hline 4. & Median & 26.00 & 2.37 & .10 & 1.67 & 15.375 & 2.44 & 7.417 \\
\hline 5. & Mode & 23 & 2 & 0 & 1 & 13 & 2 & 8 \\
\hline 6. & S. D & 4.930 & .868 & .304 & .939 & 1.8892 & .751 & 2.8015 \\
\hline 7. & Minimum & 18 & 1 & 0 & 1 & 13 & 1.751 & 2 \\
\hline 8. & Maximum & 38 & 4 & 1 & 4 & 20 & 5 & 15 \\
\hline
\end{tabular}


doses of Misoprostol 22 (55.0\%) of participant had medical induction.

The major cause of termination was mental health which was $20(50.0 \%)$, followed by fetal anomaly 10 (25.0\%), medical condition being $8(20.0 \%)$ and rape/ incest was $2(5.0 \%)$ (Table 2$)$.

Table 2. Causes of Termination of Pregnancy.

\begin{tabular}{|l|l|l|}
\hline S.N & Causes & $\mathrm{n}(\%)$ \\
\hline 1. & Mental Health & $20(50)$ \\
\hline 2. & Fetal anomaly & $10(25)$ \\
\hline 3. & Medical condition & $8(20)$ \\
\hline 4. & Rape/ incest & $2(5)$ \\
\hline & Total & $40(100)$ \\
\hline
\end{tabular}

Most of the participant had medical induction 37 $(92.5 \%)$ and $3(7.5 \%)$ medical induction were converted to $D$ \& $E$ after second dose of Misoprostol due to heavy bleeding. Time duration for medical induction was from 2 hours to 15 hours. Mean time duration was 7.215 hours (SD- 2.8015) (Table 3).

Table 3. Time Duration From Medical Induction to Abortion.

\begin{tabular}{|c|c|c|}
\hline S.N & Time Duration (Hours) & n (\%) \\
\hline 1. & 2.0 & $1(2.5)$ \\
\hline 2. & 2.5 & $1(2.5)$ \\
\hline 3. & 4.0 & $3(7.5)$ \\
\hline 4. & 4.5 & $3(7.5)$ \\
\hline 5. & 5.0 & $4(10.0)$ \\
\hline 6. & 5.5 & $1(2.5)$ \\
\hline 7. & 6.5 & $1(2.5)$ \\
\hline 8. & 7.0 & $4(10.0)$ \\
\hline 9. & 7.5 & $2(5)$ \\
\hline 10. & 8.0 & $7(17.5)$ \\
\hline 11. & 8.5 & $2(5.0)$ \\
\hline 12. & 9.5 & $2(5.0)$ \\
\hline 13. & 10.0 & $2(5.0)$ \\
\hline 14. & 11.0 & $2(5.0)$ \\
\hline 15. & 13.0 & $1(2.5)$ \\
\hline 16. & 15.0 & $1(2.5)$ \\
\hline 17. & Total & $37(92.5)$ \\
\hline 18. & $\begin{array}{l}\text { Medical Induction } \\
\text { Converted to Dilatation } \\
\text { and Evacuation ( } D \text { and } E \text { ) }\end{array}$ & $3(7.5)$ \\
\hline 19. & Grand Total & $40(100.0)$ \\
\hline
\end{tabular}

\section{DISCUSSION}

Mifepristone and Misoprostol has been used for medical induction in different regime and interval. In our study following the latest WHO recommendation Mifepristone 200 milligram was given to all the participants and Misoprostol 400 microgram was given at three hours interval till expulsionfor second trimester medical abortion.

Aniteye etal, had stated two third of major complication occurs during medical abortion in second trimester abortion but in our study, it was 3 cases $(7.5 \%)$ who had bleeding. Mentula, et al. had found medical abortion to be safe and D \& E in around one third of the cases in second trimester abortion as compared to our study the abortion was safe and D \& $E$ was in $7.5 \%$ of the cases. Gemzell, et al. had recommended combination of mifepristone and misoprostol and its effectiveness in second trimester abortion in their study, like wise in our study we use combination of mifepristone and misoprostol and it was $92.5 \%$ effective in medical induction. Ulmann, et al. had success rate of $95.3 \%$ of medical induction as compared to our study, which was $92.5 \%$. Dabash, R., et al. recorded $91.7 \%$ complete uterine evacuation after using combination of mifepristone and misoprostol as compared to our study where it was $92.5 \%$.

Karki, et al. in their study the age of women undergoing second trimester abortion was $26-30$ years, $81.11 \%$ of the women had never undergone abortion, mental cause appeared to be the major reason for abortion constituting $82.04 \%$, success was $90.58 \%$, expulsion with total five doses of misoprostol and induction to abortion time was 4-7 hours 11 which was comparable to our study, mean age was 27.45 years, $90 \%$ had never undergone abortion, $50 \%$ was mental cause, success rate was $92.5 \%$ and expulsion with total of five doses of misoprostol and induction to mean abortion time was 7.215 hours.

The limitations of the study are: being single centre study, the results can not be generalized; being crosssectional study, the association to the cause factor can not be determined and biases can be possible.

\section{CONCLUSIONS}

The combination of Mifepristone and Misoprostol have excellent result for termination of pregnancy if appropriately used after evaluating the patient with minimal complications. 


\section{REFERENCES}

1. Lalitkumar S., Bygdeman M., Gemzell-Danielsson K. Mid-trimester induced abortion: a review. Hum Reprod Update. 2007;13(1):3752. [PubMed]

2. Shah I, Ahman E. Unsafe abortion in 2008: global and regional levels and trends. Reprod Health Matters. 2010;18(36):90-101. [pubMed]

3. Aniteye P, Mayhew S. Attitudes and experiences of women admitted to hospital with abortion complications in Ghana. Afr J Reprod Health. 2011;15(1):47-55. [PubMed]

4. Mentula MJ, Niinimäki M, Suhonen S, Hemminki E, Gissler $\mathrm{M}$, Heikinheimo O. Immediate adverse events after second trimester medical termination of pregnancy: results of a nationwide registry study. Hum Reprod. 2011;26(4):927-32. [PubMed]

5. Gemzell-Danielsson K, Lalitkumar S. Second trimester medical abortion with mifeprostone-misoprostol and misoprostol alone: a review of methods and management. Reprod Health Matters. 2008;16(31):162-72. [ [

6. Ulmann A, Silvestre L, Chemama L, et al. Medical termination of early pregnancy with mifepristone (RU 486) followed by a prostaglandin analogue. Acta Obstet Gynecol Scand1992;71:278-83. [PubMed]

7. UK Multicentre Trial. The efficacy and tolerance of mifepristone and prostaglandin in first trimester of pregnancy. Br J Obstet Gynaecol. 1990;97:480-6. [uuㄹ]

8. World Health Organization. Termination of pregnancy with reduced doses of mifepristone. BMJ. 1993;307:532-7. [PubMed]

9. Ashok PW, Templeton A, Wagaarachchi PT, Flett GM. Midtrimester medical termination of pregnancy: a review of 1002 consecutive cases. Contraception. 2004 Jan;69(1):51-58. [PubMed]

10. Dabash R. A double-blind randomized controlled trial of mifepristone or placebo before buccal misoprostol for abortion at 14-21 weeks of pregnancy. Int J Gynaecol Obstet. 2015;130(1):40-44. [PubMed]

11. Karki A, Dangal, G, Pradhan H, Shrestha R, Bhattachan K. Medical and Surgical Abortion in the Second Trimester of Pregnancy. Nepal Journal of Obstetrics and Gynaecology. 2015;10(1):25-29. [Full Text]

The Author(s) 2018.

This work is licensed under a Creative Commons Attribution 4.0 International License. The images or other third party material in this article are included in the article's Creative Commons license, unless indicated otherwise in the credit line; if the material is not included under the Creative Commons license, users will need to obtain permission from the license holder to reproduce the material. To view a copy of this license, visit http://creativecommons.org/licenses/by/4.0/ 